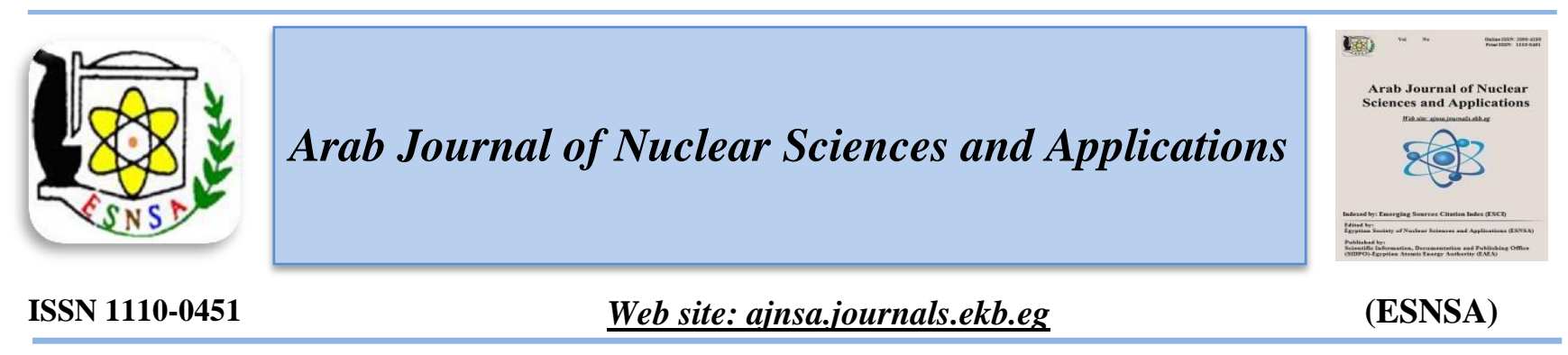

\title{
Particle Size Effect of Silica Gel on the $\gamma$-Radiation Induced Electrical Conductivity of Urea Aqueous Solutions
}

\author{
Kh. A. Sife - Eldeen \\ National Center for Radiation Research and Technology (NCRRT), Atomic Energy Authority \\ Nasr City, Cairo, Egypt
}

\begin{abstract}
Received $7^{\text {th }}$ Dec. 2019 Different concentrations $(0.1,3,6 \mathrm{M})$ of urea aqueous solutions have been irradiated with ${ }^{60} \mathrm{Co}-\gamma$-rays in Accepted $14^{\text {th }}$ Sept.
2020 induced electrical conductivity (RIC) of the irradiated solutions was measured. The RIC values of the 0.1 M solutions increase as the particle size of SG decreases i.e., the particle surface area increases. This observation points to a radiation-induced chemical reactions, which are catalyzed by SG. These reactions, probably, yield products, which increase the RIC such as urea peroxide (UP). On the other hand, a different behavior was observed in the case of 3, $6 \mathrm{M}$ solutions, where, the RIC increases as particle size increase. So, the mechanism of production of the species which increase the RIC of $0.1 \mathrm{M}$ samples is different from that in the case of $3,6 \mathrm{M}$. In all irradiated samples, the pH values tend to increase, slightly, as particle size increases. A mechanism was proposed to explain the obtained data.
\end{abstract}

Keywords: silica gel / urea / $\gamma$-radiation/ electrical conductivity / $\mathrm{pH}$

\section{Introduction}

Generally, the radiation energy absorbed by solids dissipates into three main channels: thermal, defect formation and luminescence. In heterogeneous systems, there is a competition between surface reactions and the other energy dissipation channels. In an irradiated heterogeneous system, when the two phases each constitute a significant fraction of the total mass, the ionizing energy is absorbed significantly by both phases. When charge carriers cross from one phase to another, phenomena are thus different from those observed in a homogeneous phase. The interaction of radiation with an oxide causes electronic excitations, which promote electrons from the valence band to the conduction band, leaving holes in the valence band [1].
Since the beginning of radiation chemistry, at the end of the 19th century, much work has been conducted to determine the mechanisms of water radiolysis. Consequently, radiolysis of water $[1,2]$ leads to the formation of radical species $(\mathrm{H}, \mathrm{OH}$, $\left.\mathrm{e}^{-}{ }_{\mathrm{aq}}\right)$, ions $\left(\mathrm{H}_{3} \mathrm{O}^{+}, \mathrm{OH}^{-}\right)$, and molecular products $\left(\mathrm{H}_{2} \mathrm{O}_{2}, \mathrm{H}_{2}\right)$. Water radiolysis can be written as:

$$
\mathrm{H}_{2} \mathrm{O}_{w W} \rightarrow \mathrm{e}^{-}{ }_{\text {aq, }} \mathrm{OH}, \mathrm{H}, \mathrm{O}_{2} \mathrm{H}, \mathrm{H}_{3} \mathrm{O}^{+}, \mathrm{OH}^{-}, \mathrm{H}_{2} \mathrm{O}_{2}, \mathrm{H}_{2}
$$

The radiolysis of water in contact with SG is of significant importance and is complex, where water can be strongly affected at solid/liquid interfaces, due to energy transfer from the solid to adsorbed molecules at the surface. This can be considered as radiation catalysis.

It was considered that the absorption of radiation energy is partitioned between the solution and the

Corresponding author: sifekhdr@hotmail.com

DOI: 10.21608/ajnsa.2020.20634.1307

CScientific Information, Documentation and Publishing Office (SIDPO)-EAEA 
solid particles [3]. Hence, in irradiated SG, the energy transfers to the adsorbed molecules at the surface, by positive holes and generated electrons. Some of these reactions have been formulated to explain the chemical behavior of the irradiated SG:

$$
\begin{aligned}
& \mathrm{SG}_{w w} \rightarrow \mathrm{SG}^{+}(+ \text {ve hole })+\mathrm{e}^{-} \\
& \mathrm{SG}_{W w} \longrightarrow \mathrm{SG}^{*}
\end{aligned}
$$

The excited electrons become available for reaction with solution species such as water (eq. $3)$.

$$
\begin{aligned}
& \mathrm{e}^{-}+\mathrm{n}_{2} \mathrm{O} \rightarrow \mathrm{e}^{-} \text {aq } \\
& \mathrm{SG}^{+}+\mathrm{e}^{-} \rightarrow \mathrm{SG}^{*} \\
& \mathrm{SG}^{+}+\mathrm{e}^{-} \rightarrow \mathrm{SG}^{* *}
\end{aligned}
$$

Where $\mathrm{SG}^{*}$ and $\mathrm{SG}^{* *}$ stand for the excited states of SG [4]. The deposited energy in SG, crosses the solid-liquid interface and appears in the aqueous phase as solvated electrons [5]. Holes, on the other hand, remain trapped in the silica particles [6]. Moreover, pulse radiolysis experiments of aqueous suspensions of nanometer-sized silica have proven that electrons formed in the particle migrate out in the bulk water [7]. It should be mentioned that the hydrated electron is of a great importance in the development of radiation chemistry.

Radicals escaping irradiated SG surface, would diffuse and react with a solute or become distributed more uniformly [8]. Seino et al, noted that radiolytic yield of hydrogen depends on gamma radiation dose absorbed and metal oxide particle size $[9,10]$. Radiolysis of urea aqueous solutions was studied before in different workers [11-16]. Urea is relatively stable to ionizing radiation in aqueous solutions up to $20 \mathrm{kGy}$ [11]. Moreover, it was reported that the RIC of urea aqueous solutions significantly increases upon $\gamma$ radiolysis [12, 13]. This phenomenon was attributed to the UP formation [14]. The aim of the present work is to investigate the effect of SG particle size on the radiation-induced electrical conductivity (RIC) of urea aqueous solutions.

\section{Experimental}

Urea (98\%), have been obtained from SigmaAldrich. SG was obtained from Merk (mesh 60120 for chromatographic use). The different particle sizes $(\mathrm{A}=\leq 0.16 \mathrm{~mm}, \mathrm{~B}=>0.16 \mathrm{~mm}$ $0.2 \mathrm{~mm}, \mathrm{C}=>0.2 \mathrm{~mm}-\leq 0.5 \mathrm{~mm}, \quad \mathrm{D}=0$ ), were obtained by sieving after washing SG by distilled water and drying at $100 \mathrm{C}^{\circ}$.

$20 \mathrm{ml}$ urea aqueous solutions $(0.1,3,6 \mathrm{M})$, were added to $2 \mathrm{~g}$ of the $\mathrm{SG}$ with different particle sizes in $50 \mathrm{ml}$ glass bottle with stopper. Irradiations were carried out in a ${ }^{60} \mathrm{Co} \gamma$ - source (India Gamma chamber $4000 \mathrm{~A}$, India at the NCRRT) with a dose rate of $1.25 \mathrm{kGy} \mathrm{h}^{-1}$.

\section{pH measurements}

Measurements were performed using an Orion Research model SA210 pH/meter. The measurements were carried out at room temperature after calibration using standard buffer solutions at $\mathrm{pH} 10.00$, and $\mathrm{pH} 4.00$.

\section{Electrical conductivity measurements}

The electrical conductivity was measured at room temperature using a Kent EIL5007 conductivity meter (Kent industrial measurements-Brown Boveri). The conductivity meter, with a cell constant of $1 \mathrm{~cm}^{-1}$, was calibrated using $\mathrm{NaCl}$ standard solutions [17]. The electrical conductivity of the irradiated solutions was measured immediately after irradiation.

Double-distilled water obtained from an all glass apparatus, was used in the preparation of the urea aqueous solutions and for final rinsing of all glass ware, its specific conductivity does not exceed 0.1 $\mu \mathrm{S} \mathrm{cm}^{-1}$. Each value, in the presented results, is the average of 3 measurements.

\section{Result and Discussion}

When diluted aqueous solutions are irradiated, practically, all the energy absorbed is deposited in water molecules and the observed chemical changes are brought about indirectly via the formed radical products in water. Direct action of radiolysis on the solute is, generally, unimportant in dilute solutions i.e. at solute concentrations below about $10 \%$ per weight [18]. The author of the present work suggested in a previous publication the formation of urea peroxide (UP) when urea aqueous solution is $\gamma$-irradiated [14]. Herein, it should be mentioned that UP increases the electrical conductivity of the medium $[12,13$, 15].

Accordingly, in the present study, the observed RIC can be attributed mainly to the formation of UP and $\mathrm{H}_{2} \mathrm{O}_{2}$. The effect of SG particle size on the 
RIC of urea aqueous solutions were studied at different urea concentrations; $0.1,3$ and $6 \mathrm{M}$.

\section{Effect of SG particle size on the RIC of 0.1M urea aqueous solutions}

It is well known that the surface area of the SG particles increases as the particle size decreases. The data in Table (1) indicate that as the particle size increases, the RIC decreases. This can be attributed to that the concentration of the species which increase the RIC, such as UP, increases as surface area of the SG particles increases. Consequently, it seems that SG enhances (catalyzes) the radiation induced formation of these species and consequently the RIC of the medium.

Generally, at $0 \mathrm{kGy}$ absorbed dose, the electrical conductivity increases as the particle size increases, for all concentrations. This could be attributed to that, as particle size increases the amount of adsorbed urea on the SG surface decreases and consequently the free urea in the bulk of the solution increases. But, after irradiation the highest RIC value were observed at the smallest particle size, i.e. largest surface area. This observation points to a radiation-induced chemical reaction that occurs on the surface of SG. The products of these reactions, probably, include UP, which increases the RIC of the medium [12, 13, 15]. This observation can be explained by the electron-hole $(\mathrm{e} / \mathrm{h}+)$ pairs generated in SG (eq.1) via interactions with ionizing radiation $[3,19]$. It should be mentioned that UP formation in $\gamma$ irradiated urea aqueous solutions was discussed before in a previous work [14].

The released $\mathrm{e}^{-}$from the irradiated SG (eq.3) will be hydrated by the silanol groups and residual water on the gel [17] (eq.3). Thus, the recombination of electron initially produced with positive holes may be suppressed [17]. Consequently, $\mathrm{OH}^{-}$ions are then discharged (oxidized) by the positive holes on the oxide and as a result $\mathrm{OH}$ radicals are produced $[20,21]$. Consequently, the yield of $\mathrm{H}_{2} \mathrm{O}_{2}$ increases (eq.6) $[21,22]:$

$$
\begin{gathered}
2 \mathrm{OH}^{\cdot} \rightarrow \mathrm{H}_{2} \mathrm{O}_{2} \\
\left(\mathrm{H}_{2} \mathrm{~N}\right)_{2} \mathrm{CO}+\mathrm{H}_{2} \mathrm{O}_{2} \rightleftharpoons \underset{\text { UP }}{\left(\mathrm{H}_{2} \mathrm{~N}\right)_{2} \mathrm{CO} \bullet \mathrm{H}_{2} \mathrm{O}_{2}}
\end{gathered}
$$

So, the yield of UP will also increase (eq.7). Moreover, another mechanism was proposed for the formation of $\mathrm{OH}$ via the reaction of water with ${ }^{3}$ exciton (eq.8) on the surface of SG [5]:

$$
{ }^{3} \text { Exciton }+\mathrm{H}_{2} \mathrm{O} \rightarrow \mathrm{OH}+\mathrm{H}
$$

Therefore, the yields of $\mathrm{OH}$ and, consequently, $\mathrm{H}_{2} \mathrm{O}_{2}$ and UP are expected to be related to the surface area, i.e. particle size of SG. So, this surface area effect is then gradually suppressed when the size of the silica particles is increased [5].

Table (1): Effect of particle size of silica gel on the RIC $\left(\mu \mathrm{S} . \mathrm{cm}^{-1}\right)$ of $0.1 \mathrm{M}$ urea aqueous solutions: $\mathrm{A}=\leq 0.16 \mathrm{~mm}, \mathrm{~B}=>0.16 \mathrm{~mm} \quad-0.2 \mathrm{~mm}, \mathrm{C}=>0.2 \mathrm{~mm}$ $\leq \mathbf{5 0 0} \mu \mathrm{m}, \mathrm{D}=\mathbf{0} \mathrm{mm}$

\begin{tabular}{cccc}
\hline Particle size & $0 \mathrm{kGy}$ & $3.75 \mathrm{kGy}$ & $18.13 \mathrm{kGy}$ \\
\hline $\mathrm{A}$ & 0.40 & 10.80 & 15.00 \\
B & 1.55 & 10.50 & 14.10 \\
C & 4.20 & 5.40 & 09.90 \\
D & 0.52 & 2.70 & 11.40 \\
\hline
\end{tabular}

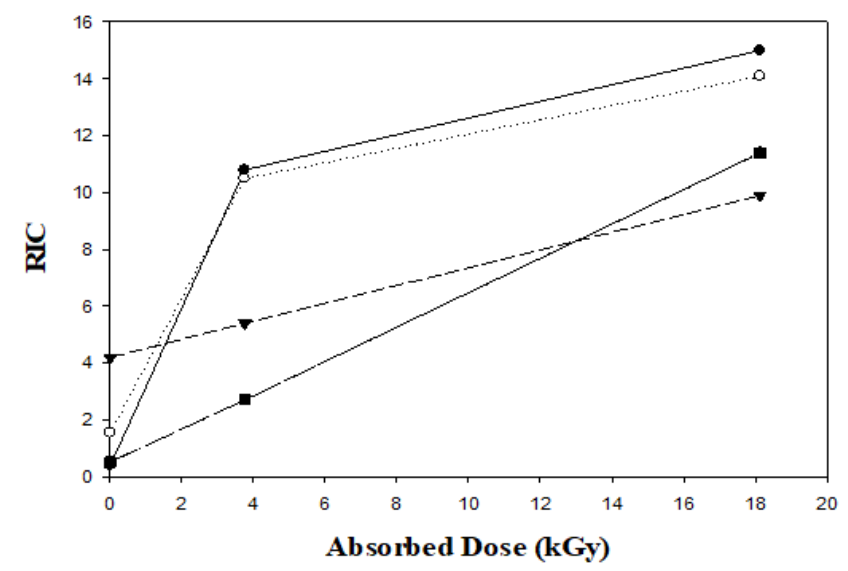

Fig. (1): Effect of absorbed radiation dose (kGy) on the

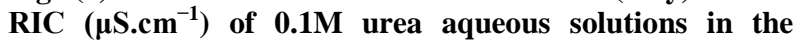
presence of different particle size of $S G$ : $10 \mathrm{~mm}$, $\leq 0.16 \mathrm{~mm}, \circ>0.16 \mathrm{~mm}-0.2 \mathrm{~mm}, \nabla>0.2 \mathrm{~mm}-\leq 500 \mu \mathrm{m}$

It seems that $\mathrm{SG}$ has a dual behavior. Where, SG catalyzes the formation of products, such as UP, and $\mathrm{H}_{2} \mathrm{O}_{2}$ which enhance the RIC. On the other hand, $\mathrm{SG}$ adsorbs different species such as UP and $\mathrm{H}_{2} \mathrm{O}_{2}$ on its surface, which, consequently, reduce the electrical conductivity of the solution. So, in 
irradiated solutions containing the largest particle size SG i.e., the smallest surface area $(>0.2 \mathrm{~mm}$ $\leq 500 \mu \mathrm{m})$, the minimum RIC value was observed. This observation can be related to the superiority of the adsorption property over the catalytic property of this particle size of SG.

Fig.(1) shows that for the $0.1 \mathrm{M}$ urea aqueous solutions, in the absence of $\mathrm{SG}(\Delta)$ as well as in the presence of SG $(\boldsymbol{\nabla},>0.2 \mathrm{~mm}-\leq 500 \mu \mathrm{m})$, RIC increases linearly as the absorbed dose increases (0-18.13 kGy). However, at a smaller particle size of SG a nonlinear increase in the RIC was observed as the absorbed dose increases (0-18.13 $\mathrm{kGy}$ ). This observation can be attributed to the increase of the effect of the adsorption property of SG as UP and $\mathrm{H}_{2} \mathrm{O}_{2}$ concentrations increase, at18.13 kGy.

Table (2): Effect of particle size of silica gel on the $\mathrm{pH}$ of $0.1 \mathrm{M}$ urea aqueous solutions $A=\leq 0.16 \mathrm{~mm}, B=>0.16 \mathrm{~mm}$ $0.2 \mathrm{~mm}, \mathrm{C}=>0.2 \mathrm{~mm}-\leq 500 \mu \mathrm{m}, \mathrm{D}=0 \mathrm{~mm}$

\begin{tabular}{cccc}
\hline Particle size & $0 \mathrm{kGy}$ & $3.75 \mathrm{kGy}$ & $18.13 \mathrm{kGy}$ \\
\hline A & 7.4 & 5.8 & 5.9 \\
B & 7.1 & 5.7 & 5.7 \\
C & 6.7 & 6 & 6.1 \\
D & 7 & 5.7 & 5.7 \\
\hline
\end{tabular}

According to the data in Table (2), it can be considered that the $\mathrm{pH}$ tends to increase as the particle size of SG increases for all the studied doses $(>0)$. This means that the concentration of the basic species increases, or acidic species decrease. It can be proposed that $\mathrm{OH}^{-}$ions are discharged (oxidized) by the loss of electrons on the SG surface via +ve holes of the $\left(\mathrm{e} / \mathrm{h}^{+}\right)$pairs and as a result $\mathrm{OH}$ radicals are produced [20]. The oxidation of $\mathrm{OH}^{-}$ions by the +ve holes depends on the amount of these holes and consequently, the surface area i.e., particle size of SG. Therefore, the yield of $\mathrm{OH}^{-}$ions will increase and, consequently the $\mathrm{pH}$, as the as particle size increases. It is apparent from Table(2) that the $\mathrm{pH}$ values of the irradiated samples, generally, decreases as the absorbed dose increases, at each particle size. This observation can be attributed to the radiationinduced formation of UP and $\mathrm{H}_{2} \mathrm{O}_{2}$. It is worthwhile to say that $\mathrm{H}_{2} \mathrm{O}_{2}$ decreases the $\mathrm{pH}$ of the medium [23]. Moreover, urea stabilizes hydrogen peroxide via formation of urea peroxide adduct [24].

Arab J. Nucl. Sci. \& Applic. Vol. 53, No. 4 (2020)
Effect of SG particle size on the RIC of 3 and $6 M$ $M$ urea aqueous solutions

The data in the Tables ( 3 and 5) clearly shows the increase of RIC as the absorbed doses increase for each particle size of SG for 3 and $6 \mathrm{M}$ urea aqueous solutions. This observation can be related to the radiation-induced formation of UP and $\mathrm{H}_{2} \mathrm{O}_{2}$ [14]. It is obvious that the magnitude of the measured RIC increases as the concentration of urea increases at the same absorbed dose and particle size. Also, the effect of SG particle sizes on the RIC at $3 \mathrm{M}$ and $6 \mathrm{M}$ is different from that of diluted solution $(0.1 \mathrm{M})$, where, at $3 \mathrm{M}$ and $6 \mathrm{M}$, the RIC decreases as particle size decreases. It seems that at high urea concentrations ( 3 and $6 \mathrm{M}$ ) another mechanism is going on, beside that followed in the case of $0.1 \mathrm{M}$ solution. This can be attributed to the predominance of the adsorption property over the catalytic effect of SG on the formation of the species which increases the RIC. So, at $3 \mathrm{M}$ and $6 \mathrm{M}$ urea concentrations, it seems that the concentration of urea is high enough to be adsorbed on SG surface and consequently hinders the electron-hole $(\mathrm{e} / \mathrm{h}+)$ pair mechanism, through which $\mathrm{H}_{2} \mathrm{O}_{2}$ and UP are produced, to some extent. Therefore, RIC decreased as SG surface area decreases due to decrease of the amount of $\mathrm{H}_{2} \mathrm{O}_{2}$ and UP. Also, as, the particle size of SG decreases the surface area of the particle size increases, consequently, the amount of the absorbed urea, $\mathrm{H}_{2} \mathrm{O}_{2}$ and UP increases. So, the decrease in RIC, as particle size decreases, can be attributed to the decreases of both free urea, $\mathrm{H}_{2} \mathrm{O}_{2}$ and UP in the bulk of the solution.

The decrease in $\mathrm{pH}$, in the case of 3 and $6 \mathrm{M}$ solutions, upon radiolysis can be attributed to the increase of the concentration of UP as well as $\mathrm{H}_{2} \mathrm{O}_{2}$ in the bulk of the solution, for all particle sizes (Tables 4 and 6).

Table (3): Effect of particle size of silica gel on the RIC $\left(\mu \mathrm{S} . \mathrm{cm}^{-1}\right)$ of $3.0 \mathrm{M}$ urea aqueous solutions: $(A=\leq 0.16 \mathrm{~mm}, \mathrm{~B}=>0.16 \mathrm{~mm}-0.2 \mathrm{~mm}, \mathrm{C}=>0.2 \mathrm{~mm}-$ $\leq 500 \mu \mathrm{m}, \mathrm{D}=\mathbf{0} \mathbf{~ m m})$

\begin{tabular}{cccc}
\hline Particle size & $0 \mathrm{kGy}$ & $3.75 \mathrm{kGy}$ & $18.13 \mathrm{kGy}$ \\
\hline A & 4.4 & 8.1 & 19.8 \\
B & 4.4 & 7.8 & 19.2 \\
C & 5.7 & 8.85 & 21.6 \\
D & 5.2 & 6.79 & 10.6 \\
\hline
\end{tabular}




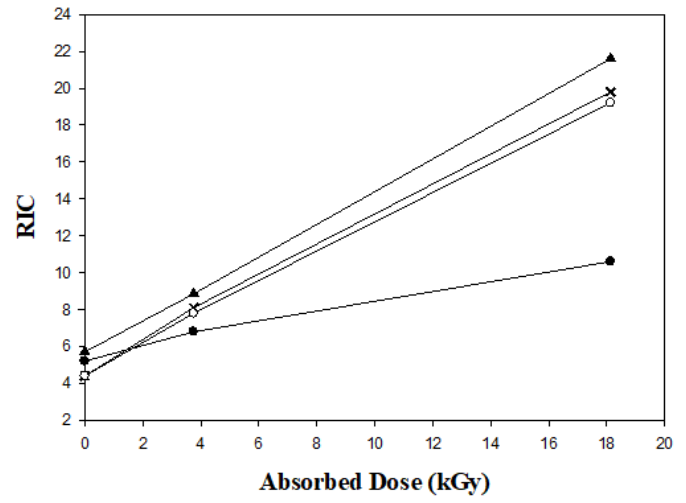

Fig. (2): Effect of absorbed radiation dose (kGy) on the RIC $\left(\mu \mathrm{S} . \mathrm{cm}^{-1}\right)$ of $3 \mathrm{M}$ urea aqueous solutions in the presence of different particle size of SG: $\nabla$ $>0.2 \mathrm{~mm}-\leq 500 \mu \mathrm{m}, X \leq 0.16 \mathrm{~mm}, \circ>0.16 \mathrm{~mm}$ $0.2 \mathrm{~mm}, \bullet 0 \mathrm{~mm}$

Table (4): Effect of particle size of silica gel on the $\mathrm{pH}$ of 3.0M urea aqueous solutions: $(A=\leq 0.16 \mathrm{~mm}$, $\mathrm{B}=>0.16 \mathrm{~mm}-0.2 \mathrm{~mm}, \mathrm{C}=>0.2 \mathrm{~mm}-\leq 500 \mu \mathrm{m}, \mathrm{D}=0$ mm)

\begin{tabular}{cccc}
\hline Particle size & $0 \mathrm{kGy}$ & $3.75 \mathrm{kGy}$ & $18.13 \mathrm{kGy}$ \\
\hline A & 6.7 & 6.3 & 6.4 \\
B & 6.9 & 6.3 & 6.4 \\
C & 7.1 & 6.5 & 6.5 \\
D & 7.8 & 6.0 & 5.7 \\
\hline
\end{tabular}

It is worthwhile to say that the measured values of the $\mathrm{pH}$ after radiolysis are smaller in the case of $0.1 \mathrm{M}$ solutions relative to that of 3 and $6 \mathrm{M}$ solutions at the same dose and particle size, where, urea in 3 and $6 \mathrm{M}$ solutions enhance the formation of $\mathrm{OH}^{-}$ions. As the adsorbed urea on the surface of SG can react with $\mathrm{e}^{-}$aq to form a urea anion (eq.9), the +ve hole $\left(\mathrm{h}^{+}\right)$can neutralizes the urea anion (eq. 10) to urea. Moreover, urea anion reacts with water producing $\mathrm{OH}^{-}$anion (eq. 11) [16].

$\mathrm{H}_{2} \mathrm{~N}-\mathrm{C}(=\mathrm{O})-\mathrm{NH}_{2}+\mathrm{e}^{-}{ }_{\text {aq }} \rightarrow\left(\mathrm{H}_{2} \mathrm{~N}-\mathrm{C}(=\mathrm{O})-\mathrm{NH}_{2}\right)$

$\left(\mathrm{H}_{2} \mathrm{~N}-\mathrm{C}(=\mathrm{O})-\mathrm{NH}_{2}\right)^{-}+\mathrm{SG}^{+}(+$ve hole $) \rightarrow \mathrm{H}_{2} \mathrm{~N}-$ $\mathrm{C}(=\mathrm{O})-\mathrm{NH}_{2}+\mathrm{SG}^{*}$

$\left(\mathrm{H}_{2} \mathrm{~N}-\mathrm{C}(=\mathrm{O})-\mathrm{NH}_{2}\right)^{-}+\mathrm{H}_{2} \mathrm{O} \rightarrow \mathrm{H}_{2} \mathrm{~N}-\mathrm{C}^{\cdot}(-\mathrm{OH})-\mathrm{NH}_{2}$ $+\mathrm{OH}^{-}$

It seems that, +ve hole $\left(\mathrm{h}^{+}\right)$prefers to neutralizing the urea anion rather than $\mathrm{OH}^{-}$ions, consequently, irradiated 3 and $6 \mathrm{M}$ solutions are more basic relative to the irradiated $0.1 \mathrm{M}$ solutions.
Table (5): Effect of particle size of silica gel on the RIC $\left(\mu \mathrm{S} . \mathrm{cm}^{-1}\right)$ of $6.0 \mathrm{M}$ urea aqueous solutions:

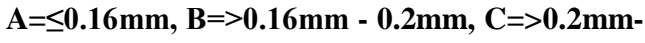
$\leq 500 \mu \mathrm{m}, \mathrm{D}=0 \mathrm{~mm})$

\begin{tabular}{cccc}
\hline Particle size & 0 kGy & $3.75 \mathrm{kGy}$ & $18.13 \mathrm{kGy}$ \\
\hline A & 6.6 & 10.5 & 26.7 \\
B & 6.8 & 10.2 & 26.4 \\
C & 7.0 & 11.4 & 27.3 \\
D & 8.2 & 9.3 & 15.3 \\
\hline
\end{tabular}

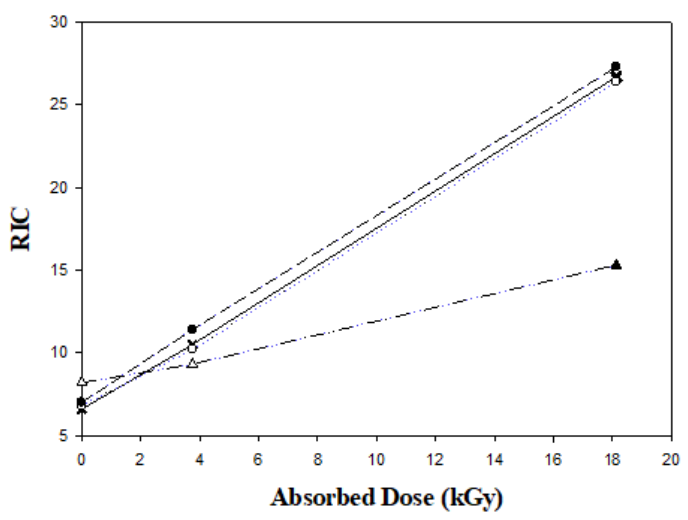

Fig. (3): Effect of absorbed radiation dose (kGy) on the RIC $\left(\mu \mathrm{S} . \mathrm{cm}^{-1}\right)$ of $6 \mathrm{M}$ urea aqueous solutions in the presence of different particle size of SG: $>0.2 \mathrm{~mm}-\leq 500 \mu \mathrm{m}, X \leq 0.16 \mathrm{~mm}, \bigcirc>0.16 \mathrm{~mm}$ $0.2 \mathrm{~mm}, \nabla 0 \mathrm{~mm}$

Figures (2 and 3) show a linear relation of the absorbed radiation dose with the RIC $\left(\mu \mathrm{S} . \mathrm{cm}^{-1}\right)$ of 3 and $6 \mathrm{M}$ urea aqueous solutions in the presence of different particle size of SG. Generally, at the same particle size and absorbed dose, RIC values increase as urea concentration increases. This effect of urea concentration can be attributed to the preferential adsorption of urea on SG [25], which will be obvious at higher concentrations ( 3 and $6 \mathrm{M}$ ), which increases $\mathrm{OH}^{-}$ions concentration (eq.11 ) and consequently $\mathrm{pH}$ will increase as well as RIC.

Table (6): Effect of particle size of silica gel on the $\mathrm{pH}$ of 6.0M urea aqueous solutions: $A=\leq 0.16 \mathrm{~mm}$, $B=>0.16 \mathrm{~mm}-0.2 \mathrm{~mm}, \mathrm{C}=>0.2 \mathrm{~mm}-\leq 500 \mu \mathrm{m}, \mathrm{D}=0 \mathrm{~mm}$ )

\begin{tabular}{cccc} 
Particle size & $0 \mathrm{kGy}$ & $3.75 \mathrm{kGy}$ & $18.13 \mathrm{kGy}$ \\
\hline A & 6.8 & 6.5 & 6.8 \\
B & 6.9 & 6.5 & 6.8 \\
C & 7 & 6.6 & 6.9 \\
D & 8 & 6.3 & 6.2 \\
\hline
\end{tabular}

\section{Conclusion}


In the current study, the variation of the RIC and $\mathrm{pH}$ values of urea aqueous solution as the particle size changed was related to the surface area of the SG particles on which the products are formed. Generally, in all the studied samples, the magnitude of RIC values increases after radiolysis. This observation can be attributed to the increase of the yield of $\mathrm{H}_{2} \mathrm{O}_{2}$ and consequently UP, beside other ionic species. It can be concluded that the effect of the particle size of SG on the RIC of $0.1 \mathrm{M}$ urea aqueous solution is different from that of 3 and $6 \mathrm{M}$, where, at $0.1 \mathrm{M}$ urea aqueous solution, the RIC decreased as the particle size of silica gel increases. So, it seems that SG enhances the radiation-induced formation of species, such as $\mathrm{H}_{2} \mathrm{O}_{2}$ and UP, consequently the RIC of the medium increases. Such observation can be related to the radiation-induced formation of electron-hole (e $/ \mathrm{h}^{+}$) pairs on SG surface. It should be mentioned that $\mathrm{OH}^{-}$ions are oxidized by the $+\mathrm{Ve}$ holes and as a result $\mathrm{OH}$ radicals are produced, consequently, the yields of $\mathrm{H}_{2} \mathrm{O}_{2}$ and UP increase, as well as , the RIC of the solutions. On the other hand, at $3 \mathrm{M}$ and $6 \mathrm{M}$, the RIC decreases as particle size decreases. Therefore, it seems that in 3 and $6 \mathrm{M}$ solutions, another mechanism is going on, beside that followed in the case of $0.1 \mathrm{M}$ solution. This can be attributed to the predominance of the adsorption property over the catalytic effect of SG. At $3 \mathrm{M}$ and $6 \mathrm{M}$ urea concentrations, it seems that the concentration of urea is high enough to be adsorbed on SG surface and consequently it hinders the electron-hole $\left(\mathrm{e} / \mathrm{h}^{+}\right)$pair mechanism, through which $\mathrm{H}_{2} \mathrm{O}_{2}$ and UP are produced, to some extent. Also, as the particle size of SG decreases (surface area increases) the amount of the absorbed urea, $\mathrm{H}_{2} \mathrm{O}_{2}$ and UP increases. Consequently, RIC decreases due to the decrease of the concentration of free urea, $\mathrm{H}_{2} \mathrm{O}_{2}$ and UP in the bulk of the solution.

In general, the decrease in $\mathrm{pH}$, in all cases, upon radiolysis can be attributed to the increase of the concentration of UP as well as $\mathrm{H}_{2} \mathrm{O}_{2}$ in the bulk of the solution. It is worthwhile to say that the measured values of the $\mathrm{pH}$ after radiolysis are smaller in the case of $0.1 \mathrm{M}$ solutions relative to that of 3 and $6 \mathrm{M}$ solutions at the same dose, where urea in 3 and $6 \mathrm{M}$ solutions enhances the formation of $\mathrm{OH}^{-}$ions. Moreover, at such high urea concentration, the oxidation of $\mathrm{OH}^{-}$ions by +ve holes is hindered by the adsorbed urea on SG surface. The magnitude of the $\mathrm{pH}$ values increases as the particle size of silica gel increases for most of the studied samples, where, the formation of acidic products ( $\mathrm{UP}$ and $\mathrm{H}_{2} \mathrm{O}_{2}$ ) is related to the +ve holes formed on the surface area of SG.

\section{Acknowledgments}

The author would like to express his sincere gratitude to Prof. A.M. Hassan Rezk for his fruitful discussions. Also, thanks should be extended to Abdelhameed, M., and Hanafy ,Kh. (NCRRT) for their technical assistance.

\section{References}

1. Le Caër S(2011) Water radiolysis: influence of oxide surfaces on $\mathrm{H}_{2}$ production under ionizing radiation. Water, 3: 235-253.

2. Spinks J W T and Woods R J(1990) An Introduction to Radiation Chemistry.third ed. John Wiley and Sons Inc., NY.

3. Fryberger T A, Janata A and Alam M (1997) Ionizing Radiation Induced Catalysis on Metal Oxide Particles. Pacific Northwest National Laboratory, Progress Report, June 1.

4. Hajime Ogura, Yoshio Tachika, Yasuo Suzuki, Chiyoko Nakazato and Masaharu Kondo(1975) Effect of Gamma Radiation on Silica Gel. Journal of Nuclear Science and Technology, 12(3):167-173.

5. Schatz T, Cook A R and Meisel D(1998) Charge carrier transfer across the silica nanoparticle/water interface. J Phys Chem B, 102: 7225-7230.

6. Dimitrijevic N M, Henglein A and Meisel, D (1999) Charge Separation across the Silica Nanoparticle/Water Interface. J Phys Chem B, 103:7073-7076.

7. Schatz T, Cook A R, Meisel D (1998) Charge Carrier Transfer across the Silica Nanoparticle/Water Interface. J. Phys. Chem. B, 102:7225-7230.

8. Allen A O (1948) Radiation Chemistry of Aqueous Solutions. J. Phys. Colloid Chem., 52: $479-490$.

9. Seino S, Yamamoto $\mathrm{T}$ A, Fujimoto $\mathrm{R}$, Hashimoto $\mathrm{K}$, Katsura M, Okuda $\mathrm{S}$ and Ohitsu K (2001) Enhancement of Hydrogen Evolution Yield from Water Dispersing Nanoparticles Irradiated with Gamma-Ray. Journal of Nuclear Science and Technology, 38 (8):633-636. 
10. Seino $\mathrm{S}$, Yamamoto $\mathrm{T}$ A, Fujimoto $\mathrm{R}$, Hashimoto K, Katsura M, Okuda S, Okitsu K and Oshima R(2001) Hydrogen evolution from water dispersing nanoparticles irradiated with gamma-ray/size effect and dose rate effect. Scripta materialia,44(8-9):1709-1712.

11. Abigail E Cruz-Hernández, Maria ColinGarcia, Alejandro Heredia-Barbero, Alicia Negron-Mendoza and Sergio RamosBernal(2015) Heterogeneous radiolysis of urea. Implications in astrobiology and prebiotic chemistry. Open Chem.,13: 172-176.

12. Sife - Eldeen Kh A (2008) Performance of Sife - Eldeen dosimeter over broad absorbed dose and dose rate ranges of $\gamma$ - radiation and at different temperatures. Iran. J. Radiat. Res.,6(3):135-140.

13. Sife - Eldeen Kh A (2008)Electrical Conductivity of Gamma Irradiated Aqueous UreaSolution and its Application for Determination of Absorbed Radiation Dose; Sife -Eldeen Dosimeter. Egypt J Sci Applic.,21: 209-220.

14. Sife - Eldeen Kh A (2019) On the Possibility of Urea Peroxide Formation in $\square$ - Irradiated Urea Aqueous Solution : A Spectroscopic Study. Arab J Nucl Sci Appl., 8( 52):70-88.

15. Sife - Eldeen Kh A (2020) Characterization of the Effect of $\square$-Radiation Absorbed Dose on the Electrical Conductivity of Aqueous Urea Solution in the Presence of Silica Gel :A Preliminary Dosimetric Study. Arab J Nucl Sci Appl, under publication.

16. Navarro-Gonzalez R, Negron- Mendoz A and Chaconr E (1989) The $\gamma$-irradiation of aqueous solutions of urea. Implications for chemical evolution. Origins of life and evolution of the biosphere,19(2):109-118.

17. Instruction Manual and Experiment Guide for the PASCO scientificModel CI-6729 (1X) and el CI-6739A (10X) Conductivity Sensor.

18. Swallow A J, Baxendale J H and Busi $\mathrm{F}(1982)$ Applications of Pulse olysis to the Study of Aqueous Organic Systems. In "The Study of Fast Processes and Transient Species by Electron Pulse Radiolysis", , D. Reidel Publishing Company, pp289-315.

19. Hajime Ogura, Masafumi Hinata, Chiyoko Nakazato, Masaharu Kondo, Teruko Sawai, Takeshi Sawai (1978) Effect of Gamma Radiation on Silica Gel, (II) Electron Scavenging on Surface of Irradiated Silica Gel by Nitrous Oxide. Journal of Nuclear Science and Technology, 15(6):433-437.

20. Christensen $\mathrm{H}(1965)$ Radiolysis of Aqueous Benzene Solutions in the Presence of Inorganic Oxides. Aktiebolaget Atomenergi Stockholm, Sweden.

21. Yongsheng Ling, Song $\mathrm{Hu}$, Ting Chen, Xionghui Fei1 , Guang Wang, Qing Shan , Daqian Hei , Huajun Feng and Wenbao Jia (2020) Efect of dose rate on degradation of 2,6-dichlorophenol by electron beam irradiation. Journal of Radioanalytical and Nuclear Chemistry, 323 :975-982.

22. Spinks J W T and Woods R J A (1990) An Introduction to Radiation Chemistry, WILEYInterscience Publication John Wiley \&. Sons, Inc.

23. USP Technology, http://www.h2o2.com.

24. Taliansky S (2005) Urea-Hydrogen Peroxide Complex. Synlett, 12:1962-1963.

25. Jens Kleinjung, and Franca Fraternal (2012)Urea-Water Solvation Forces on Prion Structures. J Chem Theory Comput,8(10):3977-3984. 